\title{
Family centered care and practice in the neonatal intensive care unit
}

\author{
Cuidado centrado na família e sua prática na unidade de terapia intensiva neonatal
}

Bruna Caroline Rodrigues ${ }^{1}$, Roberta Tognollo Borotta Uema ${ }^{1}$, Gabrieli Patrício Rissi ${ }^{1}$, Larissa Carolina Segantini Felipin $^{1}$, Ieda Harumi Higarashi ${ }^{1}$

Objective: to understand the nursing team's perception regarding family centered care and its practice in the neonatal intensive care unit. Methods: qualitative research, based on the assumptions of Family Centered Care with 19 nursing professionals. Data were analyzed using a content analysis technique. Results: two categories emerged: effective communication as the foundation of the team and family bond; interferences in the care process in the neonatal intensive care unit. Conclusion: the perception of the professionals about the reception of the family, realization of strategies to facilitate the permanence of the parents in the unit and the creation of a team and family bond, notwithstanding the social contexts of the families, as well as the inexperience, the feelings of fear with the fragile new family member and the difficulty of effective communication between the team and the family are aspects that interfere in the practice of family centered care.

Descriptors: Intensive Care Units, Neonatal; Family; Nursing, Team; Child; Infant, Premature.

Objetivo: compreender a percepção da equipe de enfermagem em relação ao cuidado centrado na família e sua prática na unidade de terapia intensiva neonatal. Métodos: pesquisa qualitativa, baseada nos pressupostos do Cuidado Centrado na Família com 19 profissionais de enfermagem. Os dados foram analisados seguindo técnica de análise de conteúdo. Resultados: emergiram duas categorias: Comunicação efetiva como alicerce do vínculo equipe e família; Interferências no processo de cuidado na unidade de terapia intensiva neonatal. Conclusão: é notória a percepção dos profissionais quanto ao acolhimento da família, realização de estratégias para facilitar a permanência dos pais na unidade e a criação de vínculo equipe e família, porém os contextos sociais das famílias, bem como a inexperiência, os sentimentos de medo com o novo membro familiar fragilizado e a dificuldade de comunicação efetiva entre equipe e família são aspectos que interferem na prática do cuidado centrado na família.

Descritores: Unidade de Terapia Intensiva Neonatal; Família; Equipe de Enfermagem; Criança; Recém-Nascido Prematuro.

\footnotetext{
${ }^{1}$ Universidade Estadual de Maringá, PR, Brazil. 


\section{Introduction}

Much has been discussed about paradigm shift, focusing on the patient and his family, aiming at the quality of life and the humanization of health care, rather than focusing on the phenomenon of the disease. One approach that has already been used in some countries is family centered care, which can be characterized as a philosophy designed to bring care to the patient and family ${ }^{(1)}$.

This model of health care presents some assumptions that must be followed in its application: dignity and respect (health professionals respect the choices, values and beliefs of the patient and the family); shared information (professionals communicate and share information in a complete and impartial manner with patients and the family); participation (patients and families are encouraged and supported to participate in decision making); and collaboration (patients and families are included and understood as the basis of support for the institution, assisting in the development of policies and programs, vocational education and care provision) ${ }^{(2)}$.

The family, recognized for its extreme importance during hospitalization, should be seen as a key element in care $^{(3)}$. The implementation of strategies focused on scheduling hospital discharge and also the humanization of care is possible through the inclusion of the family member in the care of the sick patient $t^{(4)}$.

The beneficial effects of family centered practice in the neonatal context, an area where the approach is gaining strength, are directly related to reduced parental stress and increased self-confidence at work, decreased length of hospital stay and rehospitalization, greater adhesion to the kangaroo method, strengthening the bond between newborn and family, and increased rates of breastfeeding ${ }^{(5-6)}$.

Although it presents several advantages for the health team and mainly for the patient and his family, family centered care is still little known and applied in our country. The lack of knowledge about the theme by the team influences the practice of assisting the baby and his family. A study carried out with Brazilian physicians and nurses concluded that professionals present difficulties in implementing this approach due to inadequate physical space, lack of preparation about the subject, absence of permanent education programs that address the issue, and the sociocultural profile of the population. Family centered care is still very incipient, it does not appear at various times involving the various levels of health care, much less is discussed in vocational training(7).

The health team working in a neonatal intensive care unit shows greater attention to family centered care ${ }^{(1-2,5)}$. In view of this, the following question arises: what is the real understanding of the members of the nursing team, who act directly with the patient and his family, on family centered care in a neonatal intensive care unit?

In view of the above, this research aimed to understand the perception of the nursing team regarding family centered care and its practice in the neonatal intensive care unit.

\section{Methods}

This is a qualitative research based on the assumptions of family centered care. The research was carried out with the nursing team, including seven nurses and 12 nursing technicians who work in a neonatal intensive care unit of a teaching hospital located in the northwestern region of Paraná, Brazil.

Regarding the site, it is a University Hospital located in the northwestern part of the state of Paraná that exclusively serves the Unified Health System. The neonatal intensive care unit was inaugurated 20 years ago and focuses on the treatment of infants up to 28 days of life, premature or not. This scenario includes 10 neonatal beds, four of intermediate care and six intensive care beds.

Inclusion criteria were 18 years of age or over and minimum experience of six months in the area. Exclusion criteria included participants who were on vacation or certified during the data collection period. 
The nursing team of the neonatal intensive care unit counts on 27 collaborators, being 15 nursing technicians and 12 nurses. Of that number, two refused to participate; three were on vacation and three on leave, totaling 19 participants representing all work shifts.

Data were collected between February and May 2018. The professionals were approached during the work shift and the interviews performed at the unit itself, in a place reserved for such activity. The script for a semi-structured interview, prepared by the researchers themselves, was composed of a brief socio-demographic characterization (sex, age, training and time in the area), followed by the triggering question: tell me your perception about family centered care. In addition, field diary was used to better capture contextual details and nonverbal expressions of subjects. The interviews ranged from 25 to 60 minutes (mean of 36 minutes).

In order to establish methodological rigor, the interviews were audio-taped and, later, the transcription of the speeches was done by the corresponding researcher; then the analysis and interpretation of the data were based on the reflexivity, in which the previous assumptions were recognized and left in suspension, configuring the content analysis ${ }^{(8)}$, which contemplates the following steps: 1) Pre-analysis of the data : phase of organization of raw data and systematization of ideas through floating readings; 2) Exploitation of material and formation of categories: classification of data by differentiation and regrouping according to semantic criteria to obtain thematic categories; 3) Treatment of categories obtained and interpretation: selection of significant categories along with inferences.

To maintain anonymity, the narrative fragments of each subject interviewed were coded by the letter A, representing the first letter of the alphabet, followed by a numerical numeral to simulate the order of participation.

The research was evaluated and approved by the Permanent Ethics Committee on Research Invol- ving Human Beings, under opinion no 2,092,136/2017 and Certificate of Presentation for Ethical Appreciation no 66242617,4,0000,0104. All the ethical precepts of Resolution 466/2012 of the National Health Council were contemplated, as well as the signature in the Term of Free and Informed Consent.

\section{Results}

Of the 19 subjects studied, all were female, with seven nurses and 12 nursing technicians. Age ranged from 30 to 55 years, with a mean age of 42 years. The duration of the unit ranged from two to 23 years, with seven employees working in the unit for more than twenty years.

As for specialization courses, 11 had already undergraduate latu sensu in the area of neonatology and only one possessed post-graduation stricto sensu, at master's level in nursing.

The results were thoroughly decoded, generating two thematic categories: Effective communication as a foundation of the team and family bond; Interferences in the care process in the neonatal intensive care unit.

\section{Effective communication as the foundation of the team and family bond}

In the first instance, it was possible to identify that the team covered does not directly understand what care centered on the family would be, as well as its aspects and forms of application. It was identified that the family's reception in the arrival of the newborn to the unit can be characterized as part of this referential, however we cannot say that the care centered in the family applies as a whole, nor the professionals have understanding of how deep is the application.

There was no difference in the perception of the two professional classes (nurses and nursing technicians), for which reason the data were explained together. However, it is noteworthy that most of the 
professionals, even though they were registered in the public service as nursing technicians, had a higher level in nursing or other areas. This fact may justify the absence of differences of opinion between the groups.

According to the professionals, the reception begins in the admission of the newborn in the intensive care unit, where the family is approached for general guidelines of the unit and institutional routines, as well as exchange information with the family. In fact, I think that caring for the family involves the reception, mainly because the family has to be informed, not only the care, but the information of the child's medical conduct, so I think this is essential until the treatment evolves, to family also feel safe with the care provided (A1).

The health team clearly perceives the importance of the link between professional and family, as well as the presence of this in the neonatal intensive care unit. However, shortcomings in the communication of the team and difficulties of understanding the family about what is happening with the patient interfere in the quality of the bond formed. What we see is that it does not depend on the degree of instruction for understanding our information and care, but rather how present they are with us to learn together (A13). In some cases the family has easier communication. But there are cases where the family has some social problem and it takes time to have this relationship. There are also cases that depend on the maturity of the mother in understanding what is happening (A10).

The desire for the insertion of the parents in the care provided to the newborn with the objective that this family go home being able to take care of the baby more easily was observed in several lines. We have the kangaroo method that is very important for the bond, the encouragement of the milking is a care that people cherish ... prepare the family for this new life that will be with them 24 hours a day (A4). Our goal is for the child to come out well and have contact with the mother, with the smell of the father and the mother as soon as possible, as long as the child's health allows, and for this to happen parents must speak their feelings and your doubts (A7).

Quoted several times during interviews, the mother plays a key role in the insertion of family centered care, but it is emphasized that the father was mentioned by several workers, encouraging the parti- cipation of this family member. There are parents too, I try to pay attention to the men who come, because I realize that their participation here (in the Intensive Care Unit) is increasing, they want to participate (A14). We are accustomed to always focus on the mother, but the parents are interested too, we cannot forget them (A2). These days, a father came here and asked to pick up the baby. We almost never see it, but there is a father who likes it (A5).

It was possible to identify that there is no active routine of permanent education, in which family centered care could be included, as well as the relationship of co-responsibility and co-participation in the care provided to the baby.

\section{Interferences in the care process within the neo- natal intensive care unit}

Some social problems, such as geographic distance, accessibility and family composition, were reported as difficult elements for the insertion of family centered care in a neonatal intensive care unit. Often the family resides in another county and cannot go to the unit every day or cannot stay for a longer time. Some mothers have other children and do not have adequate family support to dedicate exclusively to the newborn, besides not having the financial conditions of transportation to the unit. Unfortunately, the service cannot address all family needs in conjunction with social work and hospital psychology because of the high demand. We consider the family not only a visit, but are part of the team. Parents have the right to stay with the child, sometimes they cannot stay in the hospital for reasons beyond their control, other children, distance (A13).

One strategy observed and noted in the field diary was the use of the parents' time in the unit, that is, the team group care and guidance so that maximum information is shared between the team and the family.

The existence of other children in the family was emphatically mentioned as a factor of difficulty for the parents' stay in the institution. Sometimes we do a job with our little brothers, accompanied by psychology. This helps the family because the brothers do not understand why this child did 
not return home and because the parents are also so absent (A15). In the neonatal intensive care unit we absorb this part (of care), the mother cannot stay because she has more children, or we have to find a way to put them here in the support room, to stay longer with the child (A16).

The speeches denote the team's willingness to help the family by supporting the children's stay in support rooms while the parents spend more time with the patient. In addition, the presence of psychologists as members of the multidisciplinary team, approaching the brothers in order to clarify issues related to the baby's health and reassuring them, was another strategy highlighted by the interviewees. The family is perceived as an inseparable element of the care context and, as such, must be treated as a priority in this troubled moment of life. In unity, we try to center our attention on the mother and the father, trying to bring them to that reality they are living in: a child born out of time, it is not what they dreamed would be the perfect baby. Our priority is the baby, but the parents come together, there is no way to separate (A5).

It was observed that the health unit offers strategies to facilitate the process of guaranteeing an accessible health care system, according to the family's need, such as support for the remaining children in support rooms, while the parents stay more time with the newborn and psychological support in approaching younger children.

The professionals cited the parents' fear of staying and caring for a baby in the neonatal intensive care unit as a factor that made it difficult to insert family centered care. This occurs because the neonate has very peculiar characteristics, plus the fact that the parents do not count on the birth of a frail child. In a way, we take care of this issue of inserting the family together, but in the neonatal intensive care unit they are very afraid to stay here, so they do not stay until after the child improves (A16).

Although there is a parent's fear of caring for the premature child, the fact that they do not stay with the child in the neonatal intensive care unit is a limiting condition for the small care and procedures. $P a$ rents generally do not participate in the procedures. They are afraid to touch, to do the procedures, so when we do anything with the child they leave, they do not like to stay (A9).

The clinical condition of the child has been described as an aspect that depends on the release of parental follow-up when admitted to a neonatal intensive care unit. The family is encouraged to do some care to increase the bond of affection, to start making the touch and everything. But it is stimulated from the moment that the child is not at a critical stage (A5). When the baby is very serious, the mother stays there and can put her hand in, you cannot do much, but as the baby gets better, we teach to do oral hygiene, change diapers (A6).

Regarding the professionals, a limiting factor in the promotion of family centered care is that some workers do not recognize this philosophy in the routine of the unit; on the contrary, they infer that the assumptions are far from being reached, since there are no discussions about this model of care. We are not accustomed to this line of thinking, we do and they (parents) wait. That's why I asked you what this was: family centered. We do not argue much (A17). We should do more; really know what the mother needs, what the greater difficulty is. We leave it a little aside (the family), our concern is with the patient itself. We are failing, have to worry more and do this work (A12).

\section{Discussion}

This study is limited because it is a single neonatal intensive care unit and the subjects are restricted to the nursing team, noting that the multidisciplinary team is essential for family centered care. The team's observation that communication can be more effective between the team and family, as well as the importance of the presence of the father and the strategies used by the service to facilitate the presence of the family in the institution is configured as contributions/implications for clinical practice in the hospital environment.

The workers presented difficulties to explain the events to the family with less capacity for assimilation, motivated by the low sociocultural condition or inexperience in the exercise of the maternal/paternal 
role. The discernment of the relatives and the difficulty in the formation of the bond with the professionals hinder the process of insertion of this family in the care with the baby, causing separation between the parties.

The parents report, in a study carried out in a neonatal unit of a university hospital in São Paulo, that the information passed by the health team is not clear ${ }^{(9)}$. The continuous sharing of unbiased and complete information about child care is thus impaired when there is such a block of communication between family and staff. In addition, studies indicate that the use of technical terms causes gaps in understanding among parents of newborns ${ }^{(10-11)}$; a fact that, added to the previous ones, negatively influences the care centered in the family.

An alternative to overcome such communication problems would be to rescue, in the process of training professionals, the emphasis on ways of approaching the family with the objection of knowing, guiding them to use words that are easy to understand. In a complementary way, encouraging the routine participation of families in support groups to clarify doubts constitutes another substantial point $t^{(9,11-12)}$.

The transformation of this care reality and of the hospital environment is therefore urgent because good communication is the structural basis for the implementation of family centered care. Dialogue in a clear and concise manner aiming at link building and trust in the neonatal context is paramount for the success of communicability ${ }^{(11)}$.

It was understood that the team appreciates the insertion of the family in the care. The purpose of this intervention is to facilitate the household routine of the families, as well as the correct performance in performing basic care with the child after discharge. When it comes to hospital discharge, the implementation of an individualized educational process in the neonatal unit that encompasses the individual learning rhythm of each family member is a key point for the desired success ${ }^{(13)}$.

Although they practice communicating with fa- mily members, it is noted that care is still done in a segregated way, since the team acts and the family, in many situations, ends up being an expectant. The health team of this study demonstrated that family participation in care is an indispensable component, but it is conditioned to the level of gravity of the newborn. They report that the insertion of the family in the care is performed only after the stabilization of the baby's health, justifying that the caregivers themselves prefer not to get involved in this most critical scenario due to fear and insecurity.

Nevertheless, in the national and international scenario, studies indicate that family members prefer to stay with the loved one in the emergency room, even if they consider it to be a painful moment ${ }^{(14-15)}$. The benefits that emerged were the fact that the child was at the side of the child, offering support and security, besides accompanying what is being done during the care, soothing the suffering to see that the possible is being done ${ }^{(14)}$.

Provide the mother with the possibility of holding her baby in her womb in the first week of life, regardless of whether she is on mechanical ventilation or not, strengthens the mother-baby bond and encourages the woman to feel autonomous to take care of her child. Impairment in the actions of the mother's role, such as breastfeeding, changing diapers, bathing, hugging and kissing the child, causes feelings of loss of function in the mother, negatively impacting the mother-baby relationship ${ }^{(16)}$.

In addition, a study highlights the benefits experienced by the family when it is present in emergency settings, stressing, however, the importance of training the team to deal with the situation, otherwise negative consequences may arise ${ }^{(17)}$.

Still on this issue, an interesting finding was the fact that professionals attach great importance to the inclusion of parents (men) in care. It is incumbent on professionals to equally stimulate both parents in caring for their offspring, since studies indicate that the male tends to have greater longings due to the severity of the baby's clinical condition, leading to the 
estrangement of the child and the hospital context ${ }^{(18)}$.

Introduce the family member into care even if the child is in severe clinical condition; weekly meetings between family and health team; Kangaroo method and encouragement of lifelong education for skills are strategies to make the care of the newborn and his/her family safer and more humanized ${ }^{(6,19)}$.

Despite the difficulties mentioned, there is an effort by the employees to provide a favorable environment for building bonds, be it between family and baby, or between family and unit/team. In addition, it is possible to perceive the professionals' self-criticism by maintaining the perception that they could "do more" with regard to care for the newborn and his family. This finding of the study is relevant, since it opens possibilities for the team's own reflection on the assistance provided.

Despite the benefits of family centered care, some limitations are still part of this process, such as restrictions on human resources and lack of clarity in the implementation of family centered care, as well as reduced levels of experience on the subject, work overload, and physical and environmental resources $^{(19-20)}$.

New studies that correlate these assumptions in the practice of health care are relevant in order to trace the reality of the health units that care for premature babies, as well as to adopt strategies that implement/reinforce the use of this philosophy.

\section{Conclusion}

Although the implementation of some principles of the family centered care model in the health care practice of this research (reception, strategies to facilitate the parents' permanence in the unit, creation of a team and family bond) is notorious, another no less important finding was the non-recognition about the use of this approach by the professionals interviewed, noting that this way of caring is not discussed among them and when they refer to not knowing the foundation of the model.

\section{Acknowledgments}

The authors thank the University Hospital for the availability offered, as well as the participating professionals and the families of neonates hospitalized in a neonatal intensive care unit, who contributed to this study.

\section{Collaborations}

Rodrigues BC, Uema RTB, Rissi GP and Felipin LCS collaborated in the design, analysis and interpretation of the data, writing and critical review of the intellectual content. Higarashi IH contributed in the drafting of the project, critical review relevant intellectual content and final approval of the version to be published.

\section{References}

1. Balbino FS, Balieiro MMFG, Mandetta MA. Measurement of Family-centered care perception and parental stress in a neonatal unit. Rev LatinoAm Enfermagem. 2016; 24:e2753. doi: http:// dx.doi.org/10.1590/1518-8345.0710.2753

2. Felipin LCS, Merino MFGL, Baena JA, Oliveira RBSR, Borghesan NBA, Higarashi IH. Family-centered care in neonatal and pediatric intensive care unit: nurse's vision. Ciênc Cuid Saúde. 2018; 17(2):1-7. doi: http://dx.doi.org/10.4025/cienccuidsaude. v17i2.41001

3. Leite CCP, Souza SNDH, Rossetto EG, Pegoraro LGO, Jacinto VCB. The baby's diary to the premature infant's mother: supporting family-centered care. Rev Enferm UERJ. 2016; 24(1):e8664. doi: http:// dx.doi.org/10.12957/reuerj.2016.8664

4. Estevão AR, Teodoro FC, Pinto MNR, Freire MHS, Mazza VA. The family in nursing care for children: an integrative review. Cogitare Enferm. 2016; 21(4):1-9. doi: http://dx.doi.org/10.5380/ ce.v21i4.46551

5. Sampaio AA, Zonta JB, Ferreira FY, Okido ACC. Family-centered care in a pediatric intensive care unit: professionals' perceptions. Rev Rene. 2017; 18(4):515-20. doi: http://dx.doi. org/10.15253/2175-6783.2017000400013 
6. Sousa FCP, Montenegro LC, Goveia VR, Corrêa AR, Rocha PK, Manzo BF. Family participation in patient safety in neonatal units from the nursing perspective. Texto Contexto Enferm. 2017; 26(3):e1180016. doi: dx.doi.org/10.1590/010407072017001180016

7. Barreto MS, Arruda GO, Garcia-Vivar C, Marcon SS. Family centered care in emergency departments: perception of brazilian nurses and doctors. Esc Anna Nery. 2017; 21(2):e20170042. doi: http:// dx.doi.org/10.5935/1414-8145.20170042

8. Bardin L. Análise de conteúdo. São Paulo: Edições 70; 2016.

9. Balbino FS, Yamanaka CI, Balieiro MMFG, Mandetta MA. Parent's support group as a transforming experience for families at a neonatal unit. Esc Anna Nery. 2015; 19(2):297-302. doi: dx.doi. org/10.5935/1414-8145.20150040

10. Silva T, Alves LB, Balieiro MM, Mandetta MA, Tanner A, Shields L. Cross-cultural adaptation of an instrument to measure the family-centered care. Acta Paul Enferm. 2015; 28(2):107-12. doi: http:// dx.doi.org/10.1590/1982-0194201500019

11. Subutzki LS, Lomba ML, Backes DS. The death of neonates: the multi-professional team's perceptions of the problem in the light of its complexity. Av Enferm. 2018; 36(1):69-78. doi: dx.doi.org/10.15446/av.enferm.v36n1.65229

12. Ferreira CAG, Balbino FS, Balieiro MMFG, Mandetta MA. Family presence during cardiopulmonary resuscitation and invasive procedures in children. Rev Paul Pediatr. 2014; 32(1):107-13. doi: dx.doi. org/10.1590/S0103-05822014000100017

13. Veronez M, Higarashi IH. A protocol for hospital discharge of premature babies: input to building a proposal. Rev Enferm UERJ. 2016; 24(3):e7505. doi: dx.doi.org/10.12957/reuerj.2016.7505
14. Buboltz FL, Silveira A, Neves ET, Silva JH, Carvalho JS, Zamberlan KC. Family perception about their presence or not in a pediatric emergency situation. Texto Contexto Enferm. 2016; 25(3):e0230015. doi: dx.doi.org/10.1590/010407072016000230015

15. Hakio N, Rantanen A, Astedt-Kurki P, Suominen T. Parents' experiences of family functioning, health and social support provided by nurses - a pilot study in pediatric intensive care. Intensive Crit Care Nurs. 2015; 31(1):29-37. doi: dx.doi. org/10.1016/j.iccn.2014.08.001

16. Kegler JJ, Neves ETA, Silva AM, Jantsch LB, Bertoldo CS, Silva JH. Stress in parents of newborns in a Neonatal Intensive Care Unit. Esc Anna Nery 2019; 23(1):e20180178. doi: http://dx.doi. org/10.1590/2177-9465-ean-2018-0178

17. Silva JH, Buboltz FL, Silveira A, Neves ET, Portela JL, Jantsch LB. Family's presence during pediatric emergency care: perceptions of healthcare team members. Rev Baiana Enferm. 2017; 31(3):e17427. doi: http://dx.doi.org/10.18471/ rbe.v31i3.17427

18. Marski BSL, Custodio N, Abreu FCP, Melo DF, Wernet M. Hospital discharge of premature newborns: the father's experience. Rev Bras Enferm. 2016; 69(2):221-8. doi: http://dx.doi. org/10.1590/0034-7167.2016690203i

19. Lloyd B, Elkins M, Innes L. Barriers and enablers of patient and family centred care in an Australian acute care hospital: Perspectives of health managers. Patient Exp J [Internet]. 2018 [cited 13 Feb, 2019]; 5(3):55-64. Available from: https://pxjournal.org/cgi/viewcontent.cgi?article $=1270 \&-$ context=journal

20. Foster M, Whitehead L. Family centred care in the pediatric high dependency unit: parent's and staff's perceptions. Contemp Nurse. 2017; 53(4):489-502. doi: dx.doi.org/10.1080/103761 78.2017.1410067 